\title{
Platelet-rich plasma versus autologous blood versus steroid injection in lateral epicondylitis: systematic review and network meta-analysis
}

\author{
Alisara Arirachakaran ${ }^{1} \cdot$ Amnat Sukthuayat $^{1} \cdot$ Thaworn Sisayanarane $^{1} \cdot$ \\ Sorawut Laoratanavoraphong ${ }^{1} \cdot$ Wichan Kanchanatawan $^{2} \cdot$ Jatupon Kongtharvonskul $^{3}$
}

Received: 4 March 2015 / Accepted: 28 August 2015/Published online: 11 September 2015

(c) The Author(s) 2015. This article is published with open access at Springerlink.com

\begin{abstract}
Background Clinical outcomes between the use of platelet-rich plasma (PRP), autologous blood (AB) and corticosteroid (CS) injection in lateral epicondylitis are still controversial.

Materials and methods A systematic review and network meta-analysis of randomized controlled trials was conducted with the aim of comparing relevant clinical outcomes between the use of PRP, AB and CS injection. Medline and Scopus databases were searched from inception to January 2015. A network meta-analysis was performed by applying weight regression for continuous outcomes and a mixedeffect Poisson regression for dichotomous outcomes.

Results Ten of 374 identified studies were eligible. When compared to $\mathrm{CS}, \mathrm{AB}$ injection showed significantly
\end{abstract}

Jatupon Kongtharvonskul

Jatupon_kong@hotmail.com

Alisara Arirachakaran

amy.alisara@gmail.com

Amnat Sukthuayat

umnatgunner@gmail.com

Thaworn Sisayanarane

huey_ts@hotmail.com

Sorawut Laoratanavoraphong

arthros@gmail.com

Wichan Kanchanatawan

Wichanmd@yahoo.com

1 Orthopedics Department, Police General Hospital, Bangkok, Thailand

2 Orthopedics Department, Lerdsin General Hospital, Bangkok, Thailand

3 Section for Clinical Epidemiology and Biostatistics, Faculty of Medicine, Ramathibodi Hospital, Bangkok, Thailand improved effects with unstandardized mean differences (UMD) in pain visual analog scale (VAS), Disabilities of Arm Shoulder and Hand (DASH), Patient-Related Tennis Elbow Evaluation (PRTEE) score and pressure pain threshold (PPT) of -2.5 (95\% confidence interval, -3.5 , $-1.5),-25.5(-33.8,-17.2),-5.3(-9.1,-1.6)$ and 9.9 $(5.6,14.2)$, respectively. PRP injections also showed significantly improved VAS and DASH scores when compared with CS. PRP showed significantly better VAS with $\mathrm{UMD}$ when compared to $\mathrm{AB}$ injection. $\mathrm{AB}$ injection has a higher risk of adverse effects, with a relative risk of 1.78 $(1.00,3.17)$, when compared to CS. The network metaanalysis suggested no statistically significant difference in multiple active treatment comparisons of VAS, DASH and PRTEE when comparing PRP and AB injections. However, $\mathrm{AB}$ injection had improved DASH score and PPT when compared with PRP injection. In terms of adverse effects, $\mathrm{AB}$ injection had a higher risk than PRP injection.

Conclusions This network meta-analysis provided additional information that PRP injection can improve pain and lower the risk of complications, whereas $\mathrm{AB}$ injection can improve pain, disabilities scores and pressure pain threshold but has a higher risk of complications.

Level of evidence Level I evidence

Keywords Lateral epicondylitis · PRP - Autologous blood - Corticosteroid - Systematic review $\cdot$ Network metaanalysis

\section{Introduction}

Lateral epicondylitis is the most commonly diagnosed condition of the elbow [21], with a prevalence of 1-3\% in the general population [34]. It affects men and women 
equally, mainly in the age range of $35-55$ years $[2,28]$. In most cases of lateral epicondylitis, no obvious underlying etiology can be identified [25]. However, any activity that involves overuse of the wrist extensor or supinator muscles may be incriminating. The most commonly affected muscle is the extensor carpi radialis brevis (ECRB), as originally described by Cyriax [2]. The pathology of lateral epicondylitis was previously considered to be from tendinitis, arising as inflammation of the tendon [18]. Histopathologically, it has been shown to have a paucity of inflammatory cells such as macrophages and neutrophils [7, 11]. The condition is therefore considered to be a form of tendinosis, which is defined as a degenerative process [2]. The treatment of lateral epicondylitis includes rest, nonsteroidal anti-inflammatory medication, bracing, physical therapy, extracorporeal shock wave therapy and botulinum toxin injection. Injection of corticosteroids (once the gold standard but now considered controversial), whole blood and plateletrich plasma (PRP), and various types of surgical procedures have also been recommended [4, 8, 17, 27, 29, 35]. Injection with corticosteroids has been used since the 1950s and has been the treatment of choice for many years. However, several studies have shown no long-term beneficial effect; several alternative biologic injection therapies have therefore become available. Complex growth factor preparations, derived from the patients' own (autologous) blood, are used to drive the body's own tissue-healing mechanisms in the hope of stimulating rapid healing mechanisms [5]. Two different preparations that are most described in the literature are autologous whole blood $(\mathrm{AB})$ and platelet-rich plasma (PRP) injection $[5,10,12,14,19,21,23,24,26,33]$. There have been several randomized controlled trials (RCTs) that have compared $A B$ with PRP injection [5, 23, 24, 33], $A B$ with steroid injection[12, 26] and PRP with steroid injection $[10,14,19,21]$. However, results as to whether $\mathrm{PRP}, \mathrm{AB}$ or corticosteroids is more beneficial are still unclear. Previous systematic reviews by Krogh et al. [13] including 17 studies have shown eight different injection therapies reported by network meta-analysis. The results showed that $\mathrm{AB}, \mathrm{PRP}$ and corticosteroids were more efficacious than placebo [estimated by standardized mean difference (SMD)]; however, there were no reports comparing the efficacy of PRP versus AB, PRP versus corticosteroids and $\mathrm{AB}$ versus corticosteroids. Ahmad et al. [1] showed that PRP was more efficacious than blood injection in terms of non-response rate and conversion to surgery rates as well as pain visual analog score (VAS), and that PRP was more efficacious than corticosteroid injections in terms of pain and Disabilities of the Arm, Shoulder and Hand (DASH) score in only one of three studies, but two other studies showed no clinically significant difference. However, these meta-analyses included too few studies for pooling of the outcomes, utilized standardized mean difference, and lacked proper methodological quality required for performing a network meta-analysis. Neither heterogeneity nor sources of heterogeneity (age, sex, disease duration, preparation of the intervention and time to assess the outcome) were assessed. Moreover, other RCTs [23, 24, 26] have been published since this study was done. Therefore, a systematic review was conducted with a network metaanalysis of RCTs at multiple follow-up times with the aim of comparing relevant clinical outcomes [visual analog score, DASH score, Patient-Related Tennis Elbow Evaluation (PRTEE) score, adverse effects and non-response rates] between $\mathrm{AB}$, PRP and corticosteroids.

\section{Materials and methods}

\section{Search strategy}

The Medline and Scopus databases were used to identify relevant studies published in English from the date of inception to January 18, 2015. The PubMed and Scopus search engines were used to locate studies using the following search terms: 'lateral epicondylitis' and 'plateletrich plasma' and 'clinical trial'. Relevant studies from the reference lists of identified studies and previous systematic reviews were also explored.

\section{Selection of studies}

Identified studies were selected by one author (J.K.) and randomly checked by A.A. Their titles and abstracts were initially screened; full papers were then retrieved if a decision could not be made from the abstracts. The reasons for ineligibility or exclusion of studies were recorded and described (Fig. 1).

\section{Inclusion criteria}

Randomized controlled trials or quasi-experimental designs comparing clinical outcomes between treatments in lateral epicondylitis patients were eligible if they met the following criteria:

- compared clinical outcomes between PRP, AB and corticosteroid injection

- compared at least one of the following outcomes: visual analog score, DASH score, PRTEE score, pressure pain threshold (PPT), adverse effects and non-response rates

- had sufficient data to extract and pool, namely reported mean, standard deviation (SD), and numbers of subjects 


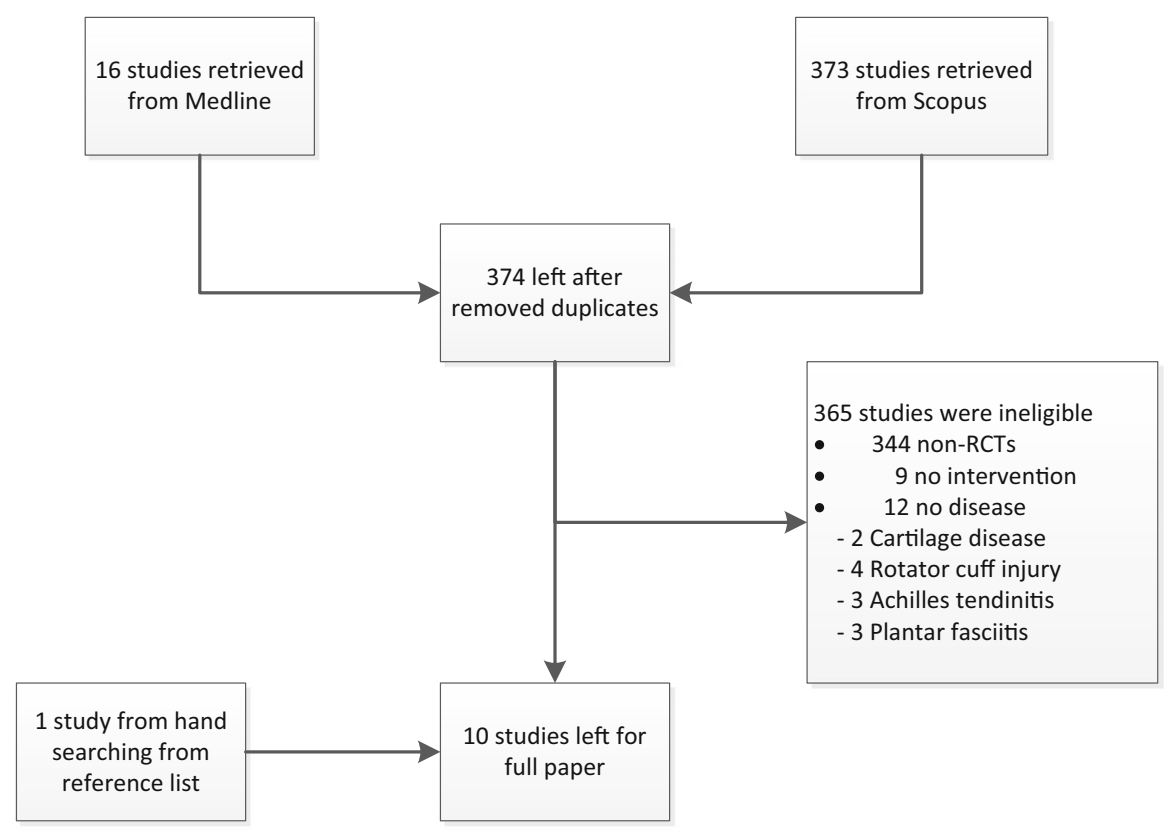

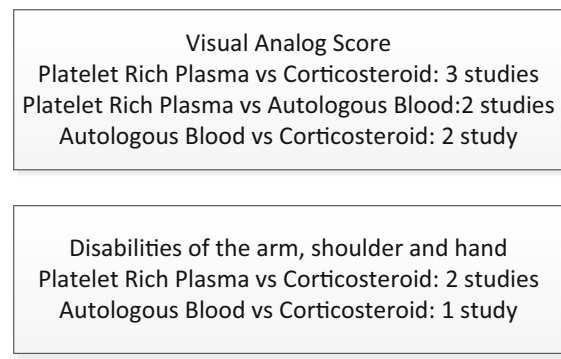

Fig. 1 Flow-chart of study selection

according to treatments for continuous outcomes; number of patients according to treatment for dichotomous outcomes

\section{Data extraction}

Two reviewers (J.K. and A.A.) independently performed data extraction using standardized data extraction forms. General characteristics of the subjects (e.g., mean age, gender, dominant side, duration of disease, pain score, disabilities scores and PPT at baseline) were extracted. The number of subjects, mean and SD of continuous outcomes, namely pain by VAS, DASH score, PRTEE score and PPT between groups, were extracted. Cross-tabulated frequencies between treatment and adverse effects were also extracted. Any disagreements were resolved by discussion and consensus with a third party (S.L.).

\section{Risk of bias assessment}

Two authors (J.K. and T.A.) independently assessed the risk of bias for each study. Six study quality domains were considered, namely sequence generation, allocation concealment, blinding (participant, personnel, and outcome assessors), incomplete outcome data, selective outcome reporting, and other sources of bias [15]. Disagreements between two authors were resolved by consensus and discussion with a third party (A.T.).

\section{Outcomes}

The outcomes of interest were pain VAS, DASH score, PRTEE score, complications and non-response rates. Methods of measurements of these outcomes were used according to the original studies. Briefly, this includes the 
VAS pain scale of 0-10, the DASH score which consists of 30 items with total scores ranging from 0 to 100 , the PRTEE which consists of pain disability and functional disability with a total score ranging from 0 to 100 , and pressure pain threshold (PPT) which was assessed by an algometer with scale units in $\mathrm{kg} / \mathrm{cm}^{2}$. Postoperative adverse effects (skin reaction and local injection site pain) and nonresponse rates were considered.

\section{Statistical analysis}

Direct comparisons of continuous outcomes measured at the end of each study between PRP, AB and corticosteroid injection were pooled using an unstandardized mean difference (UMD). Heterogeneity of the mean difference across studies was checked using the $Q$-statistic and the degree of heterogeneity was quantified using the $I^{2}$ statistic. If heterogeneity was present as determined by a statistically significant $Q$-statistic or by $I^{2}>25 \%$, the UMD was estimated using a random effects model; otherwise a fixed effects model was applied.

For dichotomous outcomes, a relative risk (RR) of adverse effect of treatment comparisons at the end of each study was estimated and pooled. Heterogeneity was assessed using the previous method. If heterogeneity was present, the Dersimonian and Laird method [3] was applied for pooling. If not, the fixed effects model by inverse variance method was applied. Meta-regression was applied to explore the source of heterogeneity (e.g., mean age, percentage of females, duration of disease, dominant hand side and follow-up time) if data was available. Publication bias was assessed using contour-enhanced funnel plots [20, 22] and Egger tests [9].

For indirect comparisons, network meta-analyses were applied to assess all possible effects of treatment if summary data was available for pooling [16, 30, 31]. A linear regression model, weighted by inverse variance, was applied to assess the treatment effects for continuous outcomes. For postoperative complications, a mixed-effect Poisson regression was applied to assess treatment effects [16]. Summary data was expanded to individual patient data using the "expand" command in STATA. Treatment was considered as a fixed effect whereas the study variable was considered as a random effect in a mixed-effect model. The pooled RR and its $95 \%$ confidence intervals (CIs) were estimated by exponential coefficients of treatments. All analyses were performed using STATA version 13.0 [32]. $P<0.05$ was considered statistically significant, except for the test of heterogeneity where $P<0.10$ was used.

\section{Results}

Sixteen and 373 studies from Medline and Scopus were identified, respectively; 15 studies were duplicates, leaving 374 studies for review of titles and abstracts. Of these, nine studies [5, 12, 14, 19, 21, 23, 24, 26, 33] plus one study [6] identified from reference lists were reviewed, leaving a total of ten studies for data extraction. Characteristics of the 10 studies [5, 6, 12, 14, 19, 21, 23, 24, 26, 33] are given in Table 1. Of seven PRP studies [5, 14, 19, 21, 23, 24, 33], the comparators included AB in four studies [5, 23, 24, 33], and steroids in three studies [14, 19, 21]. All three studies regarding $\mathrm{AB}$ were in comparison with steroids. Most studies [5, 6, 14, 21, 23, 26, 33] assessed outcomes at more than 2 months; only three studies [12, 19, 24] assessed outcomes at 1.5-2 months. Mean age, dominant side, duration of disease and VAS before treatment varied from 34 to 50 years, 57 to $85 \%, 5$ to 18 months and 5.5 to 7.6, respectively. The percentage of males ranged from 18 to $57 \%$. Various outcomes were compared between treatment groups (Fig. 1).

\section{Risk of bias in included studies}

The risk of bias assessment is described in Table 2 .

\section{Direct comparisons}

Data for direct comparisons of all treatments and outcomes measured at the end of each study are given in Table 1. Pooling according to outcomes was performed if there were at least two studies for each comparison, as clearly described below. There was no evidence of publication bias by Egger's test for both pooled effects of all outcomes from direct comparison.

\section{Visual analog score}

In seven studies [6, 12, 19, 21, 23, 24, 33], the UMD of $-1.7(95 \% \mathrm{CI}-2.6,-0.8)$ and -2.5 (95\% CI -3.5 , -1.5) showed that there was significantly lower VAS for PRP and AB, respectively, than for steroids (Table 3). The UMD was homogeneous $\left(I^{2}=0\right)$ with a value of -1.1 (95\% CI $-1.3,-0.8)$, showing that VAS was significant lower for PRP than $\mathrm{AB}$.

\section{Disabilities of the Arm Shoulder and Hand score}

In three studies $[12,19,21]$, the UMD of $-16.3(95 \% \mathrm{CI}$ $-22.3,-10.4)$ and $-25.5(95 \% \mathrm{CI}-33.8,-17.2)$ showed 


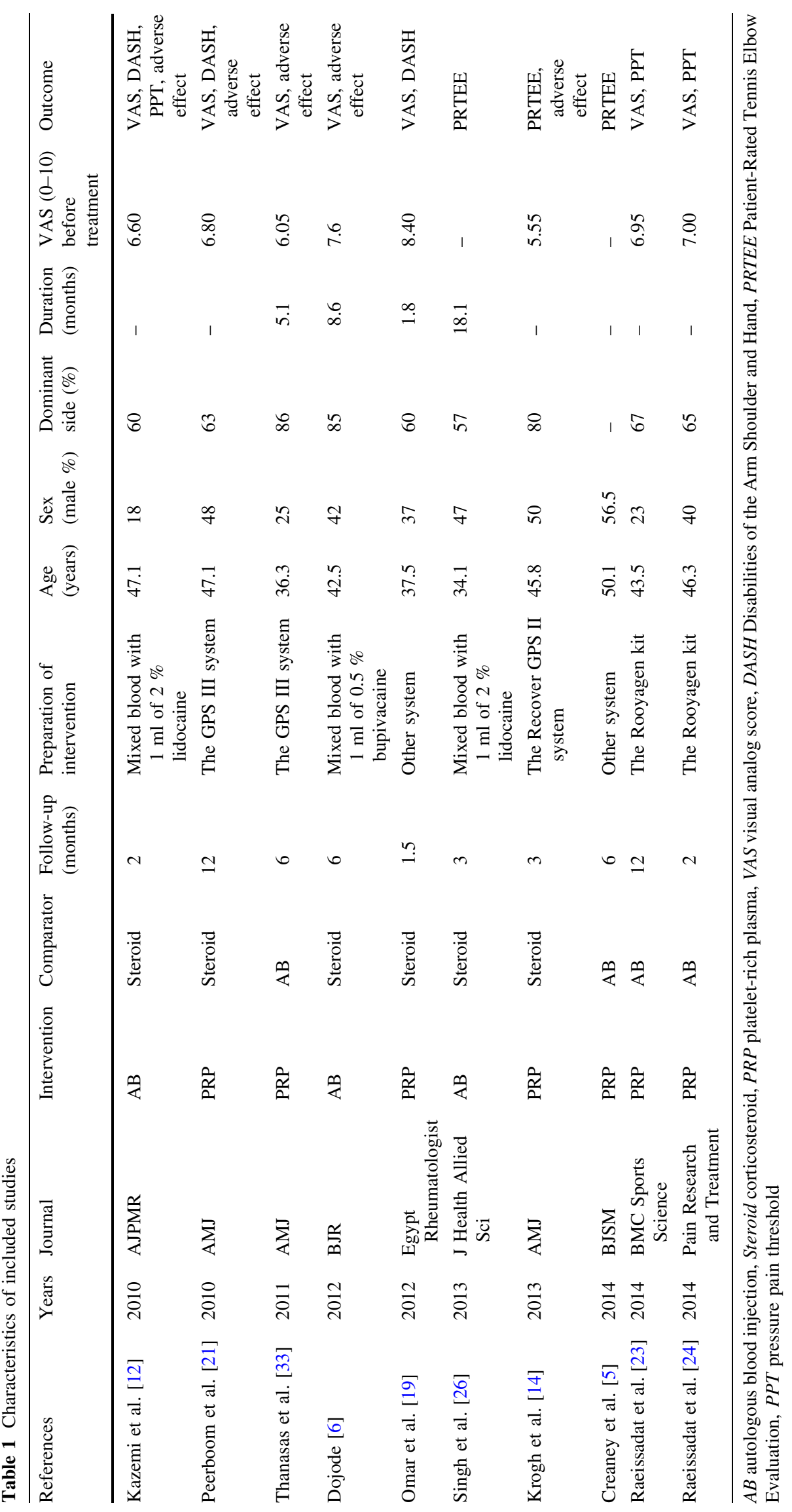


Table 2 Risk of bias assessment

\begin{tabular}{|c|c|c|c|c|c|c|c|}
\hline References & $\begin{array}{l}\text { Adequate sequence } \\
\text { generation }\end{array}$ & $\begin{array}{l}\text { Adequate allocation } \\
\text { concealment }\end{array}$ & Blinding & $\begin{array}{l}\text { Address incomplete } \\
\text { outcome data }\end{array}$ & $\begin{array}{l}\text { Selective } \\
\text { outcome report }\end{array}$ & $\begin{array}{l}\text { Free of } \\
\text { other bias }\end{array}$ & $\begin{array}{l}\text { Description of } \\
\text { other bias }\end{array}$ \\
\hline $\begin{array}{l}\text { Kazemi et al. } \\
{[12]}\end{array}$ & $\mathrm{Y}$ & $\mathrm{N}$ & $\mathrm{Y}$ & $\mathrm{N}$ & $\mathrm{Y}$ & $\mathrm{N}$ & $\begin{array}{l}\text { Did not } \\
\text { mention to } \\
\text { ITT }\end{array}$ \\
\hline $\begin{array}{l}\text { Peerboom } \\
\text { et al. [21] }\end{array}$ & $\mathrm{Y}$ & $\mathrm{Y}$ & $\mathrm{Y}$ & $\mathrm{Y}$ & $\mathrm{Y}$ & $\mathrm{Y}$ & - \\
\hline $\begin{array}{l}\text { Thanasas } \\
\text { et al. [33] }\end{array}$ & $\mathrm{Y}$ & $\mathrm{N}$ & $\mathrm{Y}$ & $\mathrm{Y}$ & $\mathrm{Y}$ & $\mathrm{Y}$ & - \\
\hline Dojode [6] & $\mathrm{U}$ & $\mathrm{N}$ & $\mathrm{N}$ & $\mathrm{Y}$ & $\mathrm{Y}$ & $\mathrm{Y}$ & - \\
\hline $\begin{array}{l}\text { Omar et al. } \\
\text { [19] }\end{array}$ & $\mathrm{U}$ & $\mathrm{N}$ & $\mathrm{N}$ & $\mathrm{N}$ & $\mathrm{Y}$ & $\mathrm{N}$ & $\begin{array}{l}\text { Per protocol } \\
\text { analysis }\end{array}$ \\
\hline $\begin{array}{l}\text { Singh et al. } \\
\text { [26] }\end{array}$ & $\mathrm{U}$ & $\mathrm{N}$ & $\mathrm{N}$ & $\mathrm{N}$ & $\mathrm{Y}$ & $\mathrm{N}$ & $\begin{array}{l}\text { Per protocol } \\
\text { analysis }\end{array}$ \\
\hline $\begin{array}{c}\text { Krogh et al. } \\
{[14]}\end{array}$ & $\mathrm{Y}$ & $\mathrm{Y}$ & $\mathrm{Y}$ & $\mathrm{Y}$ & $\mathrm{Y}$ & $\mathrm{Y}$ & - \\
\hline $\begin{array}{l}\text { Creaney } \\
\text { et al. [5] }\end{array}$ & $\mathrm{U}$ & $\mathrm{Y}$ & $\mathrm{Y}$ & $\mathrm{Y}$ & $\mathrm{Y}$ & $\mathrm{Y}$ & - \\
\hline $\begin{array}{l}\text { Raeissadat } \\
\text { et al. [23] }\end{array}$ & $\mathrm{Y}$ & $\mathrm{N}$ & $\mathrm{Y}$ & $\mathrm{N}$ & $\mathrm{Y}$ & $\mathrm{N}$ & $\begin{array}{l}\text { Per protocol } \\
\text { analysis }\end{array}$ \\
\hline $\begin{array}{l}\text { Raeissadat } \\
\text { et al. [24] }\end{array}$ & $\mathrm{Y}$ & $\mathrm{N}$ & $\mathrm{N}$ & $\mathrm{N}$ & $\mathrm{Y}$ & $\mathrm{N}$ & $\begin{array}{l}\text { Per protocol } \\
\text { analysis }\end{array}$ \\
\hline
\end{tabular}

that there was a significantly lower DASH score for PRP and $\mathrm{AB}$, respectively, than for steroids (Table 3).

\section{Patient-Related Tennis Elbow Evaluation score}

In three studies $[5,14,26]$, the UMD of -7.3 (95\% CI $-13.8,-0.9)$ and $-5.3(95 \% \mathrm{CI}-9.1,-1.6)$ showed that there was a significantly lower PRTEE score for PRP and $\mathrm{AB}$, respectively, than for steroids (Table 3). The UMD of -11.0 (95\% CI $-18.3,-3.7)$ showing that the PRTEE score was significant lower for PRP than AB.

\section{Pressure pain threshold}

In three studies [12, 23, 24], the UMD of 9.9 (95\% CI 5.6, 14.2) showed that there was a significantly higher PPT score for $\mathrm{AB}$ than steroids (Table 3). The UMD of 2.5 (95\% CI $-1.5,6.5)$ showing that PPT was higher for PRP than $\mathrm{AB}$, but this was not significant.

\section{Adverse effects (local pain and skin reaction) and non-} response rates

In five studies [6, 12, 14, 21, 33], the pooled RR was 1.78 (95\% CI 1.00, 3.17), which showed a significantly higher risk of complications after $\mathrm{AB}$ injection when compared with steroids, and no heterogeneity $\left(I^{2}=0\right)$ was present (Table 3). Compared with PRP, the pooled RR for AB and steroids had no statistically significant difference. Only one study [21] reported non-response rates. The pooled RR was 1.23 (95\% CI 1.01, 1.49), which showed a significantly higher risk of non-response after PRP injection when compared with steroid injection.

\section{Network meta-analysis}

\section{Visual analog score}

Seven studies $[6,12,19,21,23,24,33]$ were included in the network meta-analysis. After being adjusted by time, the regression analysis suggested that for assessment within 2 months, the mean differences in VAS for PRP and $\mathrm{AB}$ showed that the VAS was lower than for steroid injection, but these were not significantly different (as seen in Table 4; Fig. 2a). For assessment at the last follow-up, the mean difference in VAS for PRP and AB injection was lower, with statistical significance, than for steroid injection.

\section{Disabilities of the Arm Shoulder and Hand score}

Three studies $[12,19,21]$ were included in the network meta-analysis. After being adjusted for time frame, the regression analysis suggested that for assessment within 2 months, the mean difference in DASH score for $\mathrm{AB}$ injection was statistically significantly lower than for PRP and steroid injection, with a value of $-38.66(95 \% \mathrm{CI}$ $-56.83,20.48)$ and -24.27 (95\% CI $-40.68,7.86)$, respectively (Table 4; Fig. 2b). However, assessment at the 
Table 3 Summarized results of direct comparisons according to type of interventions

\begin{tabular}{|c|c|c|c|c|}
\hline Clinical outcomes & No. of studies & $I^{2}$ & No. of subjects & UMD $(95 \%$ CI $)$ \\
\hline \multicolumn{5}{|l|}{ VAS } \\
\hline PRP vs. AB & 3 & 0 & 72 vs. 72 & $-1.1(-1.3,-0.8)^{*}$ \\
\hline PRP vs. steroid & 2 & 77.4 & 66 vs. 64 & $-1.7(-2.6,-0.8)^{*}$ \\
\hline $\mathrm{AB}$ vs. steroid & 2 & 0 & 60 vs. 60 & $-2.5(-3.5,-1.5)^{*}$ \\
\hline \multicolumn{5}{|l|}{ DASH score } \\
\hline PRP vs. steroid & 2 & 91.6 & 96 vs. 94 & $-16.3(-22.3,-10.4)^{*}$ \\
\hline $\mathrm{AB}$ vs. steroid & 1 & - & 30 vs. 30 & $-25.5(-33.8,-17.2)^{*}$ \\
\hline \multicolumn{5}{|l|}{ PRTEE score } \\
\hline PRP vs. $A B$ & 1 & - & 80 vs 70 & $-11.0(-18.3,-3.7)^{*}$ \\
\hline PRP vs. steroid & 1 & - & 20 vs. 20 & $-7.3(-13.8,-0.9)^{*}$ \\
\hline $\mathrm{AB}$ vs. steroid & 1 & - & 30 vs. 30 & $-5.3(-9.1,-1.6)^{*}$ \\
\hline \multicolumn{5}{|l|}{ PPT } \\
\hline PRP vs. $A B$ & 2 & 68 & 58 vs. 58 & $2.5(-1.5,6.5)$ \\
\hline$A B$ vs. steroid & 1 & - & 30 vs. 30 & $9.9(5.6,14.2)^{*}$ \\
\hline Adverse effects & No. of studies & $I^{2}$ & No. of subjects & RR (95 \% CI) \\
\hline PRP vs. $\mathrm{AB}$ & 1 & - & 14 vs. 14 & $0.44(0.17,1.11)$ \\
\hline PRP vs. steroid & 2 & 0 & 71 vs. 69 & $1.00(0.31,3.24)$ \\
\hline $\mathrm{AB}$ vs. steroid & 2 & 0 & 60 vs. 60 & $1.78(1.00,3.17)^{*}$ \\
\hline Non-response rate & No. of studies & $I^{2}$ & No. of subjects & RR (95 \% CI) \\
\hline PRP vs. steroid & 1 & - & 51 vs. 49 & $1.23(1.01,1.49)^{*}$ \\
\hline
\end{tabular}

PRP platelet-rich plasma, $A B$ autologous blood, Steroid corticosteroid, VAS visual analog score, DASH Disabilities of the Arm Shoulder and Hand, PRTEE Patient-Rated Tennis Elbow Evaluation, $P P T$ pressure pain threshold, $I^{2}$ degree of heterogeneity, UMD unstandardized mean differences, $C I$ confidence interval, $R R$ relative risk

* Statistically significant difference $(P<0.05)$

last follow-up of $\mathrm{AB}$ injection was statistically significantly lower than steroid injection but not significantly different when compared with PRP.

\section{Patient-Related Tennis Elbow Evaluation score}

Data from three studies $[5,14,26]$ were included in the network meta-analysis of PRTEE score (Table 4). The lowest mean PRTEE scores were for steroid injection and PRP injection with a value of $30.82(95 \%$ CI 18.53, 43.11) and 29.31 (95\% CI 17.03, 41.60) when assessed within 2 months and at most recent follow-up, respectively. There was no significant difference between the two active treatments (Table 4).

\section{Pressure pain threshold}

Data from three studies $[12,23,24]$ were included in the network meta-analysis of PPT (Table 4). The highest mean PPT was for $\mathrm{AB}$ injection with a value of 21.23 (95\% CI $15.16,27.31)$ and 27.53 (95\% CI 21.46, 33.61) when assessed within 2 months and at last follow-up, respectively. The regression analysis suggested that the mean difference in PPT for AB injection was statistically significantly higher than for PRP and steroid injection with a value of $2.65(95 \%$ CI $0.30,5.00)$ and $3.67(95 \%$ CI $1.64,5.69)$ when assessed within 2 months and at last follow-up assessment, respectively; the mean difference between $\mathrm{PRP}$ and $\mathrm{AB}$ was statistically significant and increased to 7.50 (95\% CI 5.15, 9.85) and 9.87 (95\% CI 7.84, 11.89) (Table 4; Fig. 2c).

\section{Adverse effects (local pain and skin reaction) and non- response rates}

Data from five studies $[6,12,14,21,33]$ were included in the network meta-analysis. Compared to AB injection, PRP and steroid injection had lower risks of having complications, with borderline statistical significance of $99.6 \%$ $(\mathrm{RR}=0.004 ; \quad 95 \% \quad \mathrm{CI} \quad 0.0002,0.09)$ and $53 \%$ $(\mathrm{RR}=0.53 ; 95 \%$ CI $0.27,1.05)$, respectively. PRP injection had an approximately $10 \%(\mathrm{RR}=0.90 ; 95 \% \mathrm{CI}$ $0.36,1.27$ ), statistically not significant, lower risk than steroid injection (Table 4; Fig. 2d). 
Table 4 Comparisons of treatment effects: a network meta-analysis

\begin{tabular}{|c|c|c|c|c|c|c|c|c|}
\hline \multirow[t]{2}{*}{ Treatment } & \multicolumn{4}{|c|}{ Within 2 months } & \multicolumn{4}{|c|}{ At last follow-up } \\
\hline & $N$ & Mean & $95 \% \mathrm{CI}$ & $P$ value & $N$ & Mean & $95 \% \mathrm{CI}$ & $P$ value \\
\hline \multicolumn{9}{|l|}{ VAS } \\
\hline PRP & 153 & 3.64 & $2.84,4.45$ & $<0.001 *$ & 168 & 2.27 & $1.51,3.02$ & $<0.001 *$ \\
\hline $\mathrm{AB}$ & 132 & 2.99 & $2.19,3.80$ & $<0.001^{*}$ & 132 & 2.90 & $2.09,3.70$ & $<0.001 *$ \\
\hline Steroid & 79 & 4.18 & 3.04, 5.33, & $<0.001^{*}$ & 94 & 4.29 & $3.31,5.27$ & $<0.001 *$ \\
\hline \multirow[t]{2}{*}{ Treatment } & \multicolumn{4}{|c|}{ Within 2 months } & \multicolumn{4}{|c|}{ At last follow-up } \\
\hline & $N$ & Mean difference & $95 \% \mathrm{CI}$ & $P$ value & $N$ & Mean difference & $95 \% \mathrm{CI}$ & $P$ value \\
\hline \multicolumn{9}{|l|}{ VAS } \\
\hline PRP vs. steroid & - & -0.54 & $-1.76,0.68$ & 0.386 & - & -2.02 & $-3.04,-1.01$ & $<0.001 *$ \\
\hline $\mathrm{AB}$ vs. steroid & - & -1.19 & $-2.41,0.03$ & 0.056 & - & -1.39 & $-2.48,-0.30$ & $0.012 *$ \\
\hline PRP vs. AB & - & 0.65 & $-0.21,1.51$ & 0.138 & - & -0.63 & $-1.47,0.20$ & 0.138 \\
\hline \multirow[t]{2}{*}{ Treatment } & \multicolumn{4}{|c|}{ Within 2 months } & \multicolumn{4}{|c|}{ At last follow-up } \\
\hline & $N$ & Mean & $95 \% \mathrm{CI}$ & $P$ value & $N$ & Mean & $95 \% \mathrm{CI}$ & $P$ value \\
\hline \multicolumn{9}{|l|}{ DASH } \\
\hline PRP & 51 & 46.15 & $35.37,56.93$ & $<0.001 *$ & 66 & 17.38 & $8.42,26.33$ & $<0.001 *$ \\
\hline $\mathrm{AB}$ & 30 & 7.49 & $-7.61,22.59$ & $<0.001 *$ & 30 & 7.49 & $-7.61,22.59$ & $<0.001 *$ \\
\hline Steroid & 79 & 31.76 & $22.81,40.71$ & $<0.001 *$ & 94 & 35.95 & $28.10,43.80$ & $<0.001 *$ \\
\hline \multirow[t]{2}{*}{ Treatment } & \multicolumn{4}{|c|}{ Within 2 months } & \multicolumn{4}{|c|}{ At last follow-up } \\
\hline & $N$ & Mean difference & $95 \% \mathrm{CI}$ & $P$ value & $N$ & Mean difference & $95 \% \mathrm{CI}$ & $P$ value \\
\hline \multicolumn{9}{|l|}{ DASH } \\
\hline PRP vs. steroid & - & 14.39 & $1.77,27.00$ & $0.025^{*}$ & - & -18.58 & $-29.08,-8.08$ & $0.001 *$ \\
\hline$A B$ vs. steroid & - & -24.27 & $-40.68,-7.86$ & $0.004 *$ & - & -24.27 & $-40.68,-7.86$ & $0.004 *$ \\
\hline PRP vs. AB & - & 38.66 & $20.48,56.83$ & $<0.001 *$ & - & 9.88 & $-7.32,27.08$ & 0.260 \\
\hline \multirow[t]{2}{*}{ Treatment } & \multicolumn{4}{|c|}{ Within 2 months } & \multicolumn{4}{|c|}{ At last follow-up } \\
\hline & $N$ & Mean & $95 \% \mathrm{CI}$ & $P$ value & $N$ & Mean & $95 \% \mathrm{CI}$ & $P$ value \\
\hline \multicolumn{9}{|l|}{ PRTEE } \\
\hline PRP & 100 & 36.37 & $24.09,48.66$ & $<0.001 *$ & 100 & 29.31 & $17.03,41.60$ & $<0.001 *$ \\
\hline $\mathrm{AB}$ & 100 & 34.12 & $21.84,46.41$ & $<0.001 *$ & 100 & 33.87 & $21.59,46.16$ & $<0.001 *$ \\
\hline Steroid & 50 & 30.82 & $18.53,43.11$ & $<0.001 *$ & 50 & 32.53 & $20.24,44.82$ & $<0.001 *$ \\
\hline \multirow[t]{2}{*}{ Treatment } & \multicolumn{4}{|c|}{ Within 2 months } & \multicolumn{4}{|c|}{ At last follow-up } \\
\hline & $N$ & Mean difference & $95 \% \mathrm{CI}$ & $P$ value & $N$ & Mean difference & $95 \% \mathrm{CI}$ & $P$ value \\
\hline \multicolumn{9}{|l|}{ PRTEE } \\
\hline PRP vs. steroid & - & 5.55 & $-6.65,17.76$ & 0.373 & - & -3.22 & $-15.42,8.99$ & 0.605 \\
\hline AB vs. steroid & - & 3.30 & $-8.90,15.51$ & 0.596 & - & 1.34 & $-10.86,13.55$ & 0.829 \\
\hline PRP vs. $A B$ & - & 2.25 & $-9.96,14.46$ & 0.718 & - & -4.56 & $-16.77,7.65$ & 0.464 \\
\hline Treatment & Withi & months & & & At la & st follow-up & & \\
\hline & $N$ & Mean & $95 \% \mathrm{CI}$ & $P$ value & $N$ & Mean & $95 \% \mathrm{CI}$ & $P$ value \\
\hline PPT & & & & & & & & \\
\hline PRP & 58 & 18.58 & $12.66,24.51$ & $<0.001 *$ & 58 & 20.03 & $14.11,25.96$ & $<0.001 *$ \\
\hline $\mathrm{AB}$ & 30 & 21.23 & $15.16,27.31$ & $<0.001 *$ & 30 & 27.53 & $21.46,33.61$ & $<0.001 *$ \\
\hline Steroid & 88 & 17.57 & $11.70,23.44$ & $<0.001 *$ & 88 & 17.67 & $11.80,23.54$ & $<0.001 *$ \\
\hline
\end{tabular}


Table 4 continued

\begin{tabular}{|c|c|c|c|c|c|c|c|c|c|}
\hline \multirow[t]{2}{*}{ Treatment } & \multicolumn{5}{|c|}{ Within 2 months } & \multicolumn{4}{|c|}{ At last follow-up } \\
\hline & $N$ & & Mean difference & $95 \% \mathrm{CI}$ & $P$ value & $N$ & Mean difference & $95 \% \mathrm{CI}$ & $P$ value \\
\hline \multicolumn{10}{|l|}{ PPT } \\
\hline PRP vs. steroid & - & & 1.02 & $-0.48,2.52$ & 0.184 & - & 2.37 & $0.87,3.87$ & $0.02 *$ \\
\hline $\mathrm{AB}$ vs. steroid & - & & 3.67 & $1.64,5.69$ & $<0.001 *$ & - & 9.87 & $7.84,11.89$ & $<0.001^{*}$ \\
\hline PRP vs. $A B$ & - & & -2.65 & $-5.00,-0.30$ & $<0.001$ & - & -7.50 & $-9.85,-5.15$ & $<0.001 *$ \\
\hline \multirow[t]{2}{*}{ Treatment } & \multicolumn{5}{|c|}{ Within 2 months } & \multicolumn{4}{|c|}{ At last follow-up } \\
\hline & $N$ & & IR & $95 \% \mathrm{CI}$ & $P$ value & $N$ & IR & $95 \% \mathrm{CI}$ & $P$ value \\
\hline \multicolumn{10}{|l|}{ Adverse effects } \\
\hline PRP & - & & - & - & - & 85 & 0.10 & $0.03,0.34$ & $<0.001 *$ \\
\hline $\mathrm{AB}$ & - & & - & - & - & 74 & 0.20 & $0.06,0.65$ & $0.008^{*}$ \\
\hline Steroid & - & & - & - & - & 129 & 0.11 & $0.03,0.35$ & $<0.001^{*}$ \\
\hline \multirow[t]{2}{*}{ Treatment } & \multicolumn{5}{|c|}{ Within 2 months } & \multicolumn{4}{|c|}{ At last follow-up } \\
\hline & & $N$ & $\mathrm{RR}$ & $95 \% \mathrm{CI}$ & $P$ value & $N$ & $\mathrm{RR}$ & $95 \% \mathrm{CI}$ & $P$ value \\
\hline \multicolumn{10}{|l|}{ Adverse effects } \\
\hline PRP vs. steroid & & - & - & - & - & - & 0.90 & $0.36,2.24$ & 0.821 \\
\hline $\mathrm{AB}$ vs. steroid & & - & - & - & - & - & 1.88 & $0.95,3.72$ & 0.068 \\
\hline PRP vs. $A B$ & & - & - & - & - & - & 0.004 & $0.0002,0.09$ & $0.001 *$ \\
\hline
\end{tabular}

PRP platelet-rich plasma, $A B$ autologous blood, Steroid corticosteroid, VAS visual analog score, DASH Disabilities of the Arm Shoulder and Hand, PRTEE Patient-Rated Tennis Elbow Evaluation, $P P T$ pressure pain threshold, $C I$ confidence interval, $I R$ incident rate, $R R$ relative risk

* Statistically significant difference $(P<0.05)$

\section{Discussion}

The result of the present study was that PRP injection significantly improves pain and PRTEE score when compared with $\mathrm{AB}$ injection and steroid injection. Compared to $\mathrm{AB}$ injection, steroid injection had significantly improved disability score (DASH) and significantly improved pressure pain threshold (PPT). The chances of adverse effects from PRP injection and steroid injection were not significantly different but $\mathrm{AB}$ injection had a significantly higher chance of adverse effects when compared with steroid injection. Multiple active treatment comparisons with time adjustment indicated that within 2 months only $\mathrm{AB}$ injection showed an improvement of borderline significance (0.0056) in pain VAS, but PRP and AB injection showed a significant improvement in pain VAS when compared with steroid injections. AB injection had significantly improved DASH scores and PPT when compared with PRP and steroid injections, but $\mathrm{AB}$ injection had a statistically significantly higher risk of adverse effects when compared with PRP and steroid injections at the last follow-up assessment. For PRTEE score, there was no significant difference between the two active treatments.

The results of this study were consistent with previous meta-analyses by Ahmad et al. [1] which showed that PRP was more efficacious than $\mathrm{AB}$ injection in terms of pain VAS, and that PRP was more efficacious than steroid injections in terms of pain VAS. There is additional evidence with good methodological quality (RCT) that PRP injection and $\mathrm{AB}$ injection displays an improvement in disability scores (DASH, PRTEE) and pressure pain threshold (PPT) when compared with steroid injection. However, the highest risk of having adverse effects was with $\mathrm{AB}$ injection when compared with PRP and steroid injections.

The direct meta-analysis suggests potential benefits of $\mathrm{AB}$ injection in reducing pain, improving disabilities scores and pressure pain threshold, but increasing the risk of adverse effects when compared with steroids, whereas PRP injection can reduce pain, improve disabilities scores and pressure pain threshold, but has increased rates of nonresponse after injection when compared with steroid injections. However, for other outcomes there was no significant difference. There are limitations of direct metaanalysis from the small number of studies that evaluated each particular pair of treatments, but a network metaanalysis circumvents this problem by creating indirect comparisons between active treatments and difference in time of assessment that can identify the most effective therapy and the time period that is the most beneficial. In 


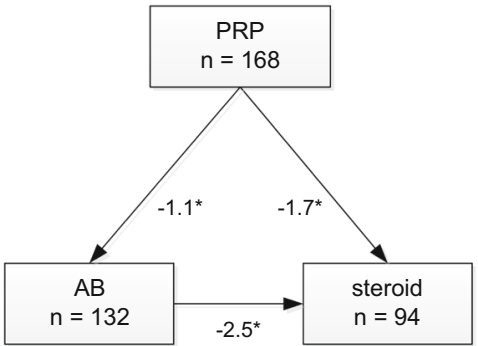

(a) Network meta-analysis of treatment

\section{effects on VAS}

A line in the figure represents treatment comparisons, with arrows and tails referring to intervention and comparators, respectively. Bold and dashed lines refer to direct and indirect comparisons, respectively. The number at the line indicates the mean VAS score of intervention vs comparator, in which $<0$ indicates favors intervention vs the comparator.

${ }^{*} \mathrm{p}<0.05$ with Bonferroni correction

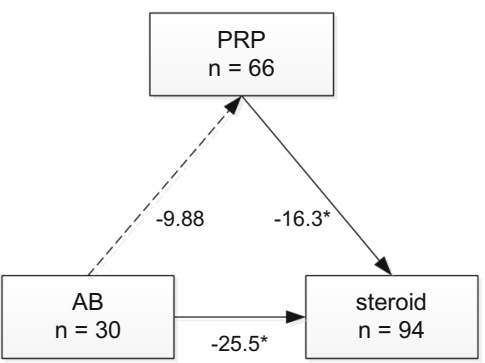

(b) Network meta-analysis of treatment

\section{effects on DASH}

A line in the figure represents treatment comparisons, with arrows and tails referring to intervention and comparators, respectively. Bold and dashed lines refer to direct and indirect comparisons, respectively. The number at the line indicates the mean DASH score of intervention vs comparator, in which < 0 indicates favors intervention vs the comparator.

* $\mathrm{p}<0.05$ with Bonferroni correction

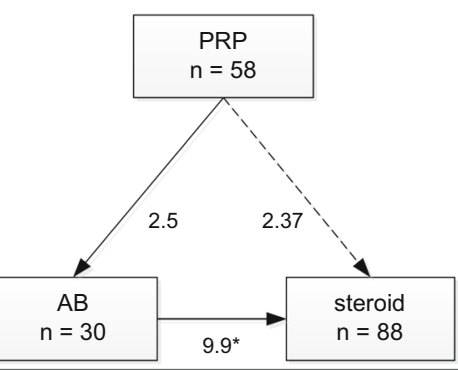

(c) Network meta-analysis of treatment effects on PPT

A line in the figure represents treatment comparisons, with arrows and tails referring to intervention and comparators, respectively. Bold and dashed lines refer to direct and indirect comparisons, respectively. The number at the line indicates the PPT of intervention vs comparator, in which $<0$ indicates favors intervention vs the comparator.

${ }^{*} \mathrm{p}<0.05$ with Bonferroni correction

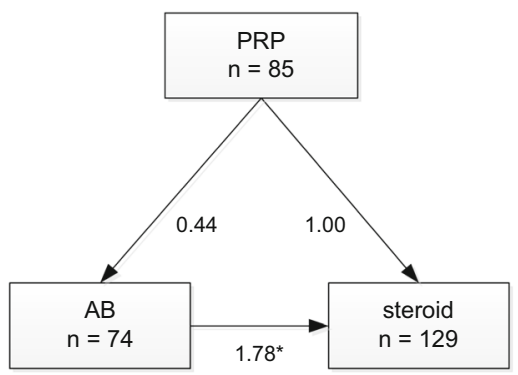

(d) Network meta-analysis of treatment effects on adverse effect

A line in the figure represents treatment comparisons, with arrows and tails referring to intervention and comparators, respectively. Bold and dashed lines refer to direct and indirect comparisons, respectively. The number at the line indicates the complication rate of intervention vs comparator, in which $<1$ indicates favors intervention vs the comparator.

${ }^{*} \mathrm{p}<0.05$ with Bonferroni correction

Fig. 2 a Network meta-analysis of effects of treatment on VAS, b network meta-analysis of effects of treatment on DASH score, $\mathbf{c}$ network meta-analysis of effects of treatment on PPT, $\mathbf{d}$ network meta-analysis of effects of treatment on adverse effects

Table 5 Summary of all treatment effects for lateral epicondylitis patients

\begin{tabular}{lllllll}
\hline Treatments & Pain VAS & DASH score & PRTEE score & PPT & Adverse effects & Non-response rate \\
\hline PRP vs. AB & $\left(D^{*} \& N\right)$ & $\left(N^{*}\right)$ & $\left(D^{*} \& N\right)$ & $\left(D \& N^{*}\right)$ & $\left(D \& N^{*}\right)$ & - \\
PRP vs. steroid & $\left(D^{*} \& N^{*}\right)$ & $\left(D^{*} \& N^{*}\right)$ & $\left(D^{*} \& N\right)$ & $\left(N^{*}\right)$ & $(D \& N)$ & $\left(D^{*}\right)$ \\
AB vs. steroid & $\left(D^{*} \& N^{*}\right)$ & $\left(D^{*} \& N^{*}\right)$ & $\left(D^{*} \& N\right)$ & $\left(D^{*} \& N^{*}\right)$ & $\left(D^{*} \& N\right)$ & - \\
\hline
\end{tabular}

$D$ direct, $N$ network

* Statistically significant difference $(P<0.05)$

this case, $\mathrm{AB}$ injection was the best therapy at the assessment times of within 2 months and over 2 months for improvement of DASH score and PPT, as during the second time period it had a cumulative effect. $\mathrm{AB}$ injection may be the worst therapy in terms of risks of adverse effects when compared with PRP and steroid injections. None of the RCTs compared combined treatments with $\mathrm{AB}$ injection or PRP injection and steroid injection.

This study has several strengths. A network meta-analysis was applied to increase the power of the tests and reduce Type I errors. A regression model was used, taking into account study effects in order to assess treatment effects. The network meta-analysis 'borrows' treatment information from other studies and increases the total sample size. As a result, treatment effects that could not be detected in direct meta-analysis could be identified. All possible treatment comparisons are mapped and displayed in Table 5. Although the pooled estimates were heterogeneous, the regression model with cluster effect takes variations at the study level into account. The limitations 
recognized in this review are that some pooled results were heterogeneous but the source of heterogeneity was not explored due to limitations in the reported data.

Based on the evidence presented, it can be concluded that when comparing three active treatments, PRP injection was the best treatment for reducing pain VAS after 2 months whereas $\mathrm{AB}$ injection was the best treatment for improving disabilities scores (DASH, PRTEE) and increasing pressure threshold (PPT) both within and after 2 months. However, AB injection had the highest risk of adverse effects (injection site pain and skin reaction). Further research should be done regarding cost-effective analysis comparing PRP injection and $\mathrm{AB}$ injection or the combination of $\mathrm{AB}$ injection and multi-modality physical therapy, possibly improving outcomes for pain, disabilities scores, and pressure pain threshold as well as lowering the risk of adverse effects.

In conclusion, this network meta-analysis has provided additional information that PRP injection or $\mathrm{AB}$ injection can be selected for management of chronic lateral epicondylitis. PRP can improve pain and lower the risk of adverse effects whereas $A B$ injection can improve pain, disabilities scores and pressure pain threshold but has a higher risk of adverse effects.

Acknowledgments All authors declare no funding source or sponsor involvement in the study design, collection, analysis and interpretation of the data, in writing the manuscript, and in submission of the manuscript for publication.

\section{Compliance with ethical standards}

Conflict of interest All authors declare that they have no conflicts of interests.

Ethical standards Not applicable as no new patients were involved in this research.

Open Access This article is distributed under the terms of the Creative Commons Attribution 4.0 International License (http://crea tivecommons.org/licenses/by/4.0/), which permits unrestricted use, distribution, and reproduction in any medium, provided you give appropriate credit to the original author(s) and the source, provide a link to the Creative Commons license, and indicate if changes were made.

\section{References}

1. Ahmad Z, Brooks R, Kang SN, Weaver H, Nunney I, Tytherleigh-Strong G, Rushton N (2013) The effect of platelet-rich plasma on clinical outcomes in lateral epicondylitis. Arthrosc J Arthrosc Relat Surg 29(11):1851-1862

2. Ahmad Z, Siddiqui N, Malik SS, Abdus-Samee M, TytherleighStrong G, Rushton N (2013) Lateral epicondylitis: a review of pathology and management. Bone Joint J 95B(9):1158-1164

3. Altman DG, Bland JM (2003) Interaction revisited: the difference between two estimates. BMJ 326(7382):219
4. Assendelft WJ, Hay EM, Adshead R, Bouter LM (1996) Corticosteroid injections for lateral epicondylitis: a systematic overview. Br J Gen Pract 46(405):209-216

5. Creaney L, Wallace A, Curtis M, Connell D (2011) Growth factor-based therapies provide additional benefit beyond physical therapy in resistant elbow tendinopathy: a prospective, single-blind, randomised trial of autologous blood injections versus platelet-rich plasma injections. $\mathrm{Br} \quad \mathrm{J}$ Sports $\mathrm{Med}$ 45(12):966-971

6. Dojode CM (2012) A randomised control trial to evaluate the efficacy of autologous blood injection versus local corticosteroid injection for treatment of lateral epicondylitis. Bone Joint Res 1(8):192-197

7. Doran A, Gresham GA, Rushton N, Watson C (1990) Tennis elbow. A clinicopathologic study of 22 cases followed for 2 years. Acta Orthop Scand 61(6):535-538

8. Edwards SG, Calandruccio JH (2003) Autologous blood injections for refractory lateral epicondylitis. J Hand Surg Am 28(2):272-278

9. Egger M, Davey Smith G, Schneider M, Minder C (1997) Bias in meta-analysis detected by a simple, graphical test. BMJ 315(7109):629-634

10. Gosens T, Peerbooms JC, Van Laar W, Den Oudsten BL (2011) Ongoing positive effect of platelet-rich plasma versus corticosteroid injection in lateral epicondylitis: a double-blind randomized controlled trial with 2 year follow-up. Am J Sports Med 39(6):1200-1208

11. Kannus P, Jozsa L (1991) Histopathological changes preceding spontaneous rupture of a tendon. A controlled study of 891 patients. J Bone Joint Surg Am 73(10):1507-1525

12. Kazemi M, Azma K, Tavana B, Rezaiee Moghaddam F, Panahi A (2010) Autologous blood versus corticosteroid local injection in the short-term treatment of lateral elbow tendinopathy: a randomized clinical trial of efficacy. Am J Phys Med Rehabil 89(8):660-667

13. Krogh TP, Bartels EM, Ellingsen T, Stengaard-Pedersen K, Buchbinder R, Fredberg U, Bliddal H, Christensen R (2013) Comparative effectiveness of injection therapies in lateral epicondylitis: a systematic review and network meta-analysis of randomized controlled trials. Am J Sports Med 41(6):1435-1446

14. Krogh TP, Fredberg U, Stengaard-Pedersen K, Christensen R, Jensen P, Ellingsen T (2013) Treatment of lateral epicondylitis with platelet-rich plasma, glucocorticoid, or saline: a randomized, double-blind, placebo-controlled trial. Am J Sports Med 41(3):625-635

15. Liberati A, Altman DG, Tetzlaff J, Mulrow C, Gotzsche PC, Ioannidis JP, Clarke M, Devereaux PJ, Kleijnen J, Moher D (2009) The PRISMA statement for reporting systematic reviews and meta-analyses of studies that evaluate health care interventions: explanation and elaboration. PLoS Med 6(7):e1000100

16. Lu G, Ades AE (2004) Combination of direct and indirect evidence in mixed treatment comparisons. Stat Med 23(20):3105-3124

17. Mishra AK, Skrepnik NV, Edwards SG, Jones GL, Sampson S, Vermillion DA, Ramsey ML, Karli DC, Rettig AC (2014) Efficacy of platelet-rich plasma for chronic tennis elbow: a doubleblind, prospective, multicenter, randomized controlled trial of 230 patients. Am J Sports Med 42(2):463-471

18. Nirschl RP (1973) Tennis elbow. Orthop Clin North Am 4(3):787-800

19. Omar AS, Ibrahim ME, Ahmed AS, Said M (2012) Local injection of autologous platelet rich plasma and corticosteroid in treatment of lateral epicondylitis and plantar fasciitis: randomized clinical trial. Egypt Rheumatol 34(2):43-49

20. Palmer TM PJ, Sutton AJ, Moreno SG (2008) Contour-enhanced funnel plots in meta-analysis. STATA J 8(2):242-254 
21. Peerbooms JC, Sluimer J, Bruijn DJ, Gosens T (2010) Positive effect of an autologous platelet concentrate in lateral epicondylitis in a double-blind randomized controlled trial: plateletrich plasma versus corticosteroid injection with a 1 year followup. Am J Sports Med 38(2):255-262

22. Peters JL, Sutton AJ, Jones DR, Abrams KR, Rushton L (2008) Contour-enhanced meta-analysis funnel plots help distinguish publication bias from other causes of asymmetry. J Clin Epidemiol 61(10):991-996

23. Raeissadat SA, Rayegani SM, Hassanabadi H, Rahimi R, Sedighipour L, Rostami K (2014) Is platelet-rich plasma superior to whole blood in the management of chronic tennis elbow: 1 year randomized clinical trial. BMC Sports Sci Med Rehabil 6(1):12. doi:10.1186/2052-1847-6-12

24. Raeissadat SA, Sedighipour L, Rayegani SM, Bahrami MH, Bayat M, Rahimi R (2014) Effect of platelet-rich plasma (PRP) versus autologous whole blood on pain and function improvement in tennis elbow: a randomized clinical trial. Pain Res Treat. doi: $10.1155 / 2014 / 191525$

25. Shiri R, Viikari-Juntura E, Varonen H, Heliovaara M (2006) Prevalence and determinants of lateral and medial epicondylitis: a population study. Am J Epidemiol 164(11):1065-1074

26. Singh A, Gangwar DS, Shekhar (2013) Autologous blood versus corticosteroid local injection for treatment of lateral epicondylosis: a randomized clinical trial. Online J Health Allied Sci 12(2): 11

27. Smidt N, Assendelft WJ, Arola H, Malmivaara A, Greens S, Buchbinder R, van der Windt DA, Bouter LM (2003) Effectiveness of physiotherapy for lateral epicondylitis: a systematic review. Ann Med 35(1):51-62
28. Smidt N, van der Windt DA (2006) Tennis elbow in primary care. BMJ 333(7575):927-928

29. Smidt N, van der Windt DA, Assendelft WJ, Deville WL, Korthals-de Bos IB, Bouter LM (2002) Corticosteroid injections, physiotherapy, or a wait-and-see policy for lateral epicondylitis: a randomised controlled trial. Lancet 359(9307):657-662

30. Song F, Altman DG, Glenny AM, Deeks JJ (2003) Validity of indirect comparison for estimating efficacy of competing interventions: empirical evidence from published meta-analyses. BMJ 326(7387):472

31. Song F, Harvey I, Lilford R (2008) Adjusted indirect comparison may be less biased than direct comparison for evaluating new pharmaceutical interventions. J Clin Epidemiol 61(5):455-463

32. Stata/SE 11.0 for windows (32bit). 13 July 2009 (updated 13 July 2009; cited). (13 July 2009)

33. Thanasas C, Papadimitriou G, Charalambidis C, Paraskevopoulos I, Papanikolaou A (2011) Platelet-rich plasma versus autologous whole blood for the treatment of chronic lateral elbow epicondylitis: a randomized controlled clinical trial. Am J Sports Med 39(10):2130-2134

34. Verhaar JA (1994) Tennis elbow. Anatomical, epidemiological and therapeutic aspects. Int Orthop 18(5):263-267

35. Wong SM, Hui AC, Tong PY, Poon DW, Yu E, Wong LK (2005) Treatment of lateral epicondylitis with botulinum toxin: a randomized, double-blind, placebo-controlled trial. Ann Intern Med 143(11):793-797 